\title{
Habitação de interesse social em cenários de revalorização urbana: considerações a partir da experiência carioca
}

\author{
Social housing in urban revalorization contexts: \\ considerations from the Rio de Janeiro experience
}

João Carlos Carvalhaes dos Santos Monteiro

\begin{abstract}
Resumo
0 artigo tem por objetivo contribuir para o debate acadêmico em torno da incorporação do componente habitacional nas recentes experiências de revalorização de áreas urbanas centrais brasileiras. São apresentadas as conclusões obtidas a partir de uma pesquisa sobre a produção habitacional de interesse social na área central do Rio de Janeiro. As reflexões expostas são apoiadas numa análise do Programa Novas Alternativas, criado em 1996 pelo poder público municipal com o objetivo declarado de fomentar a produção habitacional nos bairros centrais da capital fluminense. Realizamos uma revisão das publicações institucionais da prefeitura sobre o tema e entrevistas com o quadro técnico do programa. Através desses elementos buscamos desvendar os componentes discursivos que embasam as ações do poder público municipal carioca em sua prática de fomento à produção habitacional Palavras-chave: áreas centrais; revalorização urbana; habitação de interesse social; Rio de Janeiro; Programa Novas Alternativas.
\end{abstract}

\section{Abstract}

This article aims at contributing to the academic debate on the incorporation of the housing component into recent experiences of revalorization of urban downtown areas in Brazil. It presents the results found by a study about the production of social housing in downtown Rio de Janeiro. The reflections presented here derive from an analysis of a program called Novas Alternativas (New Alternatives), created in 1996 by the local government with the declared objective of encouraging home building in the central neighborhoods of Rio de Janeiro's capital city. Through a review of the municipal government's institutional publications about the theme and interviews with the program's staff, this article uncovers the discursive components that support the actions of Rio de Janeiro's local government in promoting the construction of home building.

Keywords: central districts; urban revalorization; social housing; Rio de Janeiro; Novas Alternativas Program. 


\section{Introdução}

Após décadas de abandono por parte dos poderes públicos e de desinvestimento do capital imobiliário, as áreas centrais de inúmeras cidades brasileiras vêm passando por uma gradativa revalorização simbólica e econômica, fenômeno apoiado na ampliação de um discurso oficial que evoca a necessidade de reverter supostos processos de "degradação" identificados nesses espaços. A "revitalização" tornou-se um imperativo nos programas de governo de diferentes siglas partidárias, atravessando mandatos e afirmando-se como uma responsabilidade incontornável das gestões públicas. Nesse contexto, inúmeros planos, programas e projetos vêm sendo apresentados por prefeituras, governos estaduais e esfera federal comprometidos com a reversão do que se convencionou chamar "crise" dos centros urbanos.

Em muitos casos, as estratégias apresentadas nesses documentos estão respaldadas por exemplos internacionais supostamente bem-sucedidos e baseiam-se num discurso que entende a revalorização dos centros como peça-chave para o desenvolvimento social e econômico à escala urbana e mesmo metropolitana. 0 imperativo da revitalização, fundamentado em críticas à ociosidade da infraestrutura instalada, à monofuncionalização e à degradação do espaço público, vem a reboque de um questionamento mais amplo das realizações do urbanismo modernista. Dentre os princípios que regem os receituários de revitalização, destacam-se frequentemente propostas baseadas na valorização do patrimônio edificado, na reanimação cultural, no incentivo à mistura de usos e, em muitos casos, no estancamento de processos de esvaziamento populacional e na retomada do crescimento demográfico dos centros urbanos.

Constata-se que, se em alguns desses projetos a questão habitacional é alijada, em outros o debate ganha destaque como elemento estruturador para desencadear a almejada "revitalização". Nesse último caso, o poder público exerce um papel fundamental, seja por meio do investimento direto em produção habitacional de interesse social, seja por meio da criação de condições facilitadoras para a atuação do capital imobiliário - tais como a flexibilização de normas urbanísticas, o rezoneamento e obras de reurbanização do espaço público.

De uma forma ou de outra, a defesa do adensamento populacional dos centros urbanos ganha amplitude, sendo festejado pela grande mídia, apoiado por setores da academia e reivindicado por movimentos sociais. Especialistas defendem as "cidades compactas" como um novo modelo de urbanização sustentável, no qual os centros adensados teriam papel fundamental para a diminuição do espraiamento urbano e de todas as consequências nefastas desse processo (Hillman, 1996). Entre os urbanistas inspirados na retórica internacional de mixité sociale, as áreas centrais são concebidas como espaços privilegiados para a promoção da integração de diferentes classes sociais e da reversão dos atuais padrões de segregação urbana. Para o capital imobiliário, os centros tornam-se uma nova fronteira urbana a ser conquistada, com grande potencial de lucratividade por meio da renda diferencial gerada (Smith, 1996). No âmbito dos movimentos de luta pela moradia, a permanência de populações de baixa renda em áreas centrais surge como uma das principais bandeiras de um projeto utópico de cidade democrática. 
É nesse contexto que o presente artigo tem por objetivo contribuir para o debate em torno da incorporação do elemento habitacional nas recentes experiências de revalorização de áreas urbanas centrais brasileiras. São apresentadas as conclusões obtidas a partir de uma pesquisa sobre a produção habitacional de interesse social na área central do Rio de Janeiro. As reflexões expostas são apoiadas numa análise do Programa Novas Alternativas, criado em 1996 pelo poder público municipal com o objetivo declarado de fomentar a produção habitacional nos bairros centrais da capital fluminense. A partir de uma revisão das publicações institucionais da Prefeitura sobre o tema e de entrevistas com o quadro técnico que compõe o programa, buscou-se desvendar os componentes discursivos que embasam as ações do poder público municipal carioca em sua prática de fomento à produção habitacional. Entrevistas com os moradores contemplados com unidades habitacionais do programa complementam o debate, revelando pontos negligenciados ou ocultos no discurso oficial. ${ }^{1}$

0 artigo está dividido em três partes. Primeiramente, realizou-se uma breve descrição do fenômeno de revalorização da área central do Rio de Janeiro. Partiu-se de uma perspectiva histórica que contempla o período de recrudescimento dos processos de esvaziamento populacional e desinteresse do capital imobiliário até o momento presente, em que se observa uma retomada de investimentos privados e a criação do projeto de "revitalização" da antiga zona portuária, denominada operação urbana Porto Maravilha. A segunda parte do artigo relata a incorporação do componente habitacional por diferentes propostas de intervenção em centros urbanos, abordando as experiências pioneiras do Banco Nacional de Habitação no final dos anos 1970 e sua captura por movimentos de luta pela reforma urbana e moradia a partir da década de 1980 . Ao final, discute-se a experiência carioca de fomento à habitação de interesse social nos bairros centrais da cidade, questionando a compatibilidade entre 0 processo de revalorização urbana em curso e a possibilidade de reversão dos atuais padrões de segregação espacial.

\section{A revalorização da área central do Rio de Janeiro}

Os bairros da chamada área central do Rio de Janeiro atravessaram um vigoroso processo de esvaziamento demográfico, popularização e degradação do ambiente construído a partir da segunda metade do século XX. A ação do poder público alinhada aos interesses do capital imobiliário recrudesceu esse processo ao incentivar a expansão da fronteira urbana da cidade e ao eleger o centro como o espaço nevrálgico do projeto rodoviarista em curso (Abreu, 2006). A migração de uma ampla parcela da classe média para os novos bairros é coincidente ao incremento de estratos de baixa renda na área central carioca, uma população que se apropria do espaço construído - tornado obsoleto ou inutilizável para as novas necessidades do circuito superior da economia (Santos, 1979) para sua reprodução social. Legislações e zoneamentos que incompatibilizavam a mistura de usos e a diversidade funcional, aliados ao desinteresse do capital imobiliário em investir na área, completaram o cenário que no último quartel do século $\mathrm{XX}$ seria caracterizado, pela 
mídia e pelo poder público, como de "crise", "degradação" e "declínio".

0 discurso público referente à reversão do processo de "degradação" da área central carioca ganha forma a partir dos anos 1980, apoiado na reabilitação do patrimônio histórico e arquitetônico. Mas é a partir da década de 1990 que as intenções complexificam-se em um conjunto de políticas urbanas, majoritariamente formuladas pelo poder público municipal. Durante as gestões César Maia (1993-1997; 2001-2009) e Luiz Paulo Conde (1997-2001), a retórica da revitalização é estruturadora de uma série de intervenções que buscavam desenvolver um mercado de produção e consumo cultural para o centro. A chamada "requalificação" do espaço público é também acionada pelo discurso oficial, concretizando-se a partir de obras de reurbanização, paisagismo e combate ao comércio ambulante. Buscava-se com essas ações, criar condições para a reanimação da atividade comercial e do mercado imobiliário da área central, um típico processo de revalorização urbana apoiado pelo investimento direto do poder público. A opção de restringir essas intervenções ao chamado central business district carioca - um setor mais propenso a reproduzir os "efeitos multiplicadores" do investimento ${ }^{2}$ - garantiram que amplas parcelas do centro passassem incólumes à ação do poder público municipal, possibilitando assim a manutenção de populações de baixa renda nelas residentes e a continuidade das atividades relacionadas ao circuito inferior da economia urbana (Santos, 1979).

Nos últimos quinze anos, indícios de reinvestimento do capital imobiliário, inclusive no ramo residencial, e a consolidação de atividades turísticas e recreativas no setor prioritário de intervenção respaldaram a hipótese difundida pela mídia e pelo poder público municipal de uma reversão do processo de "degradação" da área central. Essa nova realidade é, em grande medida, resultado da adoção de um modelo de planejamento e gestão baseado no empresariamento urbano (Harvey, 1989), caracterizado pelo city marketing, pela privatização de atribuições tradicionalmente pertencentes ao poder público e pela criação de um ambiente favorável para os investimentos privados.

Nesse contexto, a inserção do componente habitacional como instrumento de revalorização dos bairros centrais torna-se usual no discurso do poder público municipal, constatada na análise de diferentes relatórios produzidos pela Prefeitura no período em questão. Esses documentos apontam a necessidade de "[...] atrair novas famílias para os imóveis desocupados, após sua recuperação, promovendo diversidade socioeconômica na área" (Prefeitura, 2003a, p. 10), de garantir a "[...] intensificação do uso residencial de classe média e, na sequência, de população carente, visando a estimular uma saudável multiplicidade de usos e diversidade social" (Prefeitura, 2005, p. 12), além de evocarem a urgência de uma "[...] mudança de imagem [...] necessária para atrair novos habitantes e investidores, paralelamente a uma política social que garanta a diversidade" (BID; PCRJ; Apur, 2008, p. 5). A fala do Secretário Municipal de Urbanismo à época, Alfredo Sirkis, durante o lançamento de um conjunto residencial na região da Lapa, centro da cidade, é emblemática do ideário de revitalização promovido pelo poder público: "É a classe média que dará a tônica da revitalização. Já há investidores estrangeiros interessados em 
desenvolver projetos semelhantes na região. Só faltam os cariocas". ${ }^{3}$

Dando continuidade a esse processo, em 2009, a criação do projeto Porto Maravilha uma operação urbana amparada na "revitalização" da antiga zona portuária do Rio de Janeiro - possibilitou a incorporação de um território de $5 \mathrm{~km}^{2}$ à lógica de revalorização. ${ }^{4}$ Com vistas a assegurar a viabilidade dos investimentos, o projeto prevê a transformação física e simbólica de bairros historicamente ocupados por uma população de baixa renda e até então pouco afetada pela dinâmica de revalorização em curso, transformando-os numa extensão do central business district carioca e num novo polo de turismo da cidade (Monteiro e Andrade, 2012). A operação está sendo viabilizada mediante a venda de Certificados de Potencial Adicional de Construção (Cepacs) títulos comprados do poder público que conferem aos investidores imobiliários a autorização de construir além do coeficiente de aproveitamento básico previamente estabelecido. Para empreendimentos residenciais, definiu-se que a proporção de Cepacs por $\mathrm{m}^{2}$ necessária seria menor em relação a investimentos de uso comercial, sinalizando que mais uma vez o adensamento populacional seria acionado como elemento propulsor da revalorização dos bairros centrais. Essa orientação é reafirmada com a aprovação da Lei n 5780 (22/7/2014) e da Lei Complementar $n^{0} 143$ (4/8/2014), ambas de autoria do poder executivo municipal, que estabelecem condições de incentivo e benefícios fiscais para a produção habitacional e para a reconversão ou utilização de edificações existentes para fins residenciais no perímetro da operação urbana. ${ }^{5}$

\section{0 lugar da habitação em contextos de revalorização urbana}

Nesse cenário de revalorização, a incorporação do componente habitacional surge tardiamente no discurso do poder público municipal carioca. No contexto nacional, no entanto, o debate sobre o fomento à produção habitacional em áreas centrais tem origem no início da década de 1970, no âmbito das discussões em torno da preservação do patrimônio ambiental urbano. Em um contexto de absoluta supremacia do padrão periférico de urbanização, concretizado em grande medida pelas ações do Banco Nacional de Habitação (BNH), os documentos produzidos por Azevedo (1973; 1978) defendiam a inclusão do uso habitacional em projetos de restauração patrimonial, rompendo, no plano conceitual, com o paradigma de museificação reinante nas intervenções em centros históricos brasileiros naquele período. Em meados dos anos 1980, a ideia ganha adesão entre técnicos do BNH, que através de um acordo com a prefeitura de Olinda, Pernambuco, promovem um projet-piloto de reforma de imóveis residenciais tombados, numa experiência que seria expandida para outras cidades brasileiras (Bosi, 1986). Nesse período, o debate envolvendo a questão habitacional em áreas urbanas consolidadas era espacialmente concentrado no perímetro dos chamados "núcleos históricos", e o componente habitacional despontava como elemento de um objetivo mais amplo de preservação do patrimônio edificado.

É somente no final dos anos 1980 que o ideário do direito à cidade ganha destaque nos 
debates acerca da produção habitacional em áreas centrais. Na gestão Luiza Erundina (19891993), o "Programa de Habitações Populares da Região Central de São Paulo" pode ser considerado um marco nesse sentido, atuando na construção e reforma de imóveis para populações encortiçadas. Se nas propostas anteriores prevalecia o caráter patrimonial das intervenções, houve nesse programa a introdução de elementos que compunham o conjunto de demandas dos movimentos de luta por moradia e pela reforma urbana, tais como a autogestão, a participação social na formulação dos projetos e a permanência integral das famílias atingidas pelas obras. Em parte, esses movimentos sociais promoveram a ampliação de suas reivindicações - antes centradas na melhoria das condições de habitabilidade nas franjas periféricas - e passaram a contemplar também a luta pelo direito à moradia nos centros urbanos. Baseados em um discurso de contraposição entre "centro" e "periferia", - em que o "centro" representaria o espaço da integração social, do direito à cidade, do acesso aos serviços, à mobilidade e ao trabalho, enquanto a "periferia" expressaria a segregação, a exclusão, a precariedade e a continuidade dos padrões espoliativos do modelo capitalista de urbanização - os movimentos de luta por moradia e pela reforma urbana da capital paulista afirmam-se hoje como uma das maiores entidades mobilizadoras da América Latina, servindo de inspiração para organizações sociais desse tipo em diversas cidades brasileiras. ${ }^{6}$

No meio acadêmico e entre os formuladores de políticas públicas, o relativo sucesso dessas experiências pioneiras gerou uma considerável adesão discursiva quanto à viabilidade e à pertinência da inclusão do componente habitacional em programas de revalorização urbana. Todavia, acontecimentos econômicos e políticos adiariam a continuidade e a ampliação dessas ações. A extinção do BNH em 1986 e a decorrente descentralização da política habitacional provocaram não apenas um desmantelamento do conhecimento produzido pelos projetos- piloto formulados e implementados pelo órgão, mas também a quase total interrupção da produção pública de moradias. ${ }^{7}$ Na capital paulista, sob as gestões de Celso Pitta e Paulo Maluf, o projeto de cidade inclusiva da gestão precedente foi esvanecido e os programas habitacionais para a área central cancelados.

Para diversos setores, os processos de descentralização e municipalização das políticas habitacionais representaram a possibilidade da ampliação da eficácia e da eficiência das ações públicas em torno da questão da moradia em um contexto de reabertura política e reorganização dos movimentos sociais. Esses processos também geraram a expectativa de assimilação de princípios democráticos e inclusivos na sua formulação (Cardoso e Ribeiro, 2002). No entanto, essas aspirações foram freadas por uma conjuntura desfavorável, marcada tanto pela extinção do $\mathrm{BNH}$ quanto pela crise econômica, que privilegiou uma política orçamentária restritiva aos investimentos no setor de habitação. Nas grandes cidades, todavia, as limitações foram menos impactantes, tanto pela disponibilidade de recursos próprios para o fomento à produção habitacional, quanto pela capacidade de contrair grandes empréstimos de organismos internacionais financiadores. 


\section{A experiência carioca}

No Rio de Janeiro, a descentralização da política habitacional culminou com a criação da Secretaria Municipal de Habitação (SMH) em 1994, órgão composto por um conjunto de gerências, dentre as quais o Programa Novas Alternativas (PNA). ${ }^{8}$ Em seus primeiros anos, 0 PNA desempenhou a função de conceber soluções habitacionais através de projetos que se propunham "inovadores", tais como o resgate à tipologia de "vilas residenciais", a recuperação de edifícios em ruínas e a reforma de imóveis encortiçados (Prefeitura, 2003b). Inicialmente, os projetos eram concebidos de forma dispersa no território da cidade, abrangendo bairros centrais e periféricos. No entanto, em sua segunda fase, essa característica foi alterada e o programa passou a concentrar sua ação nos bairros centrais cariocas. Como discutido mais adiante, essa modificação alinhava-se ao discurso de "revitalização" do centro da cidade, fomentado pelas gestões César Maia e Luiz Paulo Conde. Entre 1998 e 2005, o PNA promoveu a reforma e a construção de dez imóveis na área central do Rio de Janeiro, totalizando 119 unidades habitacionais (Tabela 1). Os dois primeiros empreendimentos, concebidos como projetos-piloto, foram reformados com recursos próprios da Prefeitura. Eram compostos por unidades do tipo "estúdio", sem quartos, com área de serviço e banheiro coletivos. A partir de 2003, o volume de inaugurações foi intensificado graças a um acordo do programa com a Caixa Econômica Federal (CEF), que passa a disponibilizar suas linhas de crédito habitacional (crédito associativo e arrendamento residencial) para projetos de "revitalização" de sítios históricos. Esses projetos passaram a contar com unidades de um quarto, além de banheiros individualizados para adequarem-se às normas exigidas pelo banco. Apesar do número irrisório de moradias produzidas, o PNA é frequentemente citado como experiência bem-sucedida de incorporação do componente habitacional em projetos de "revitalização" urbana, tendo servido de inspiração para ações desse tipo em outras cidades brasileiras.

A sobrevivência do programa nos últimos vinte anos, atravessando incólume três gestões municipais, sugere que a promoção do adensamento populacional na área central do Rio de Janeiro conformou-se como uma ideia-força radicada no poder público municipal. Tal continuidade - atípica na história das gestões municipais cariocas - aliada a um reconhecimento positivo do programa entre determinadas organizações sociais e ambientes acadêmicos ditos progressistas despertaram a necessidade de avaliar a atuação da Prefeitura, mais especificamente do PNA, no fomento à produção habitacional na zona central da cidade. ${ }^{9}$

Que princípios regem as ações do programa? Quais motivos garantiram sua continuidade nos últimos vinte anos? De que maneira e sob quais condições esta produção habitacional vem sendo viabilizada?

Buscou-se responder essas questões a partir de uma reflexão crítica em torno do discurso oficial - legitimador da existência do PNA e da prática de fomento à produção habitacional na área central do Rio de Janeiro - promovido pelo poder público municipal. Constatou-se que, sob o argumento de oferecer moradias para famílias de baixa renda, o programa tem como princípio a revalorização dos bairros centrais cariocas. Em outras palavras, através do 
Tabela 1 - Imóveis produzidos e reabilitados pelo PNA (1998-2005)

\begin{tabular}{|c|c|c|c|c|c|c|}
\hline Empreendimento & Financiamento & $\begin{array}{c}\mathrm{N}^{\circ} \text { de } \\
\text { unidades }\end{array}$ & $\begin{array}{l}\text { Tipo de } \\
\text { unidades }\end{array}$ & $\begin{array}{c}\text { Área } \\
\text { média da } \\
\text { UH }\left(\mathrm{m}^{2}\right)\end{array}$ & Lojas & $\begin{array}{c}\text { Ano de } \\
\text { comercialização }\end{array}$ \\
\hline Travessa do Mosqueira, 20 & Recursos municipais & 9 & Habitação coletiva & 18 & 0 & 1998 \\
\hline Rua Sacadura Cabral, 295 & Recursos municipais & 16 & Habitação coletiva & 13 & 1 & 1998 \\
\hline Rua Senador Pompeu, 34 & Recursos municipais e PAR & 23 & 1 quarto & 20 & 2 & 2003 \\
\hline Rua de Santanna, 119 & $\begin{array}{c}\text { Imóvel na planta/Crédito } \\
\text { Associativo }\end{array}$ & 13 & 1 quarto & 35 & 6 & 2003 \\
\hline Rua Francisco Muratori, 38 & $\begin{array}{c}\text { Imóvel na planta/Crédito } \\
\text { Associativo }\end{array}$ & 11 & 1 quarto & 26 & 0 & 2004 \\
\hline Ladeira João Homem, 35 & PAR & 5 & 1 e 2 quartos & 48 & 0 & 2005 \\
\hline Rua Joaquim Silva, 122 & PAR & 26 & 1 quarto & 32 & 0 & 2005 \\
\hline Rua do Teatro, 21 & PAR & 6 & 2 quartos & 36 & 1 & 2005 \\
\hline Rua do Livramento, 145 & PAR & 5 & 1 quarto & 33 & 1 & 2005 \\
\hline Rua do Livramento, 147 & PAR & 5 & 1 quarto & 28 & 0 & 2005 \\
\hline Total & & 119 & & & 11 & \\
\hline
\end{tabular}

Fonte: Elaborado a partir de documentos disponibilizados pelo PNA.

PNA, a Prefeitura instrumentaliza a habitação de interesse social como um propulsor da ensejada "revitalização" do centro, creditando à reforma de edifícios tombados e à construção de novos imóveis em vazios urbanos o papel de agentes multiplicadores da reanimação econômica e da reativação do mercado imobiliário dos entornos contemplados pelas intervenções.

O PNA funciona como um programa de reabilitação na medida em que ele propõe, além de restauração, outros projetos de caráter urbanístico, onde novas edificações possam ajudar a recompor o tecido urbano bastante degradado da área central. A Prefeitura pretende assim romper com o grau de degradação dessa área usando a habitação como agente impulsionador dessa reabilitação urbana. (Informação verbal fornecida por arquiteto e gerente do PNA em fevereiro de 2010)

Nesta lógica, os projetos habitacionais desenvolvidos são concebidos como referenciais de viabilidade técnica, "modelos" bem-sucedidos de intervenção arquitetônica que têm, por objetivo, persuadir o capital imobiliário a investir na área central da cidade. Para tal, o programa se oferece como agência facilitadora para os empresários interessados em realizar tais tipos de empreendimentos, fornecendo apoio técnico e know-how para superar os possíveis desafios burocráticos. 
A ideia não é reformar todos os casarões, nem criar oferta para toda a demanda que existe. Nosso objetivo é mostrar como o poder público pode desimpedir os caminhos para que o mercado veja essas intervenções como algo interessante, para assim poder voltar a oferecer habitação na área central [...] 0 maior objetivo não é fazer habitação no Centro, é começar habitação no Centro, só que é muito difícil vender uma ideia sem ter alguns exemplos que mostrem aos proprietários e construtores que é viável construir nessa área [...] A grande responsável pela reabilitação dessa área será a iniciativa privada. (Informação verbal fornecida por arquiteto e gerente do PNA em fevereiro de 2010)

As entrevistas com os técnicos responsáveis pelo programa demonstram que esta prerrogativa mercadológica é acompanhada por uma dissociação das intervenções em relação à perspectiva de inclusão social preconizada pelos movimentos de luta por moradia e reforma urbana. Essas entrevistas expõem a discordância dos técnicos quanto à produção de unidades habitacionais para famílias de baixa renda em imóveis patrimoniais argumentando-se que moradores com rendimentos inferiores a 10 salários mínimos dificilmente arcariam com os custos de manutenção exigidos por esse tipo de edificação. Quando questionados sobre a possibilidade de auxílio técnico do PNA à reforma de imóveis ocupados por movimentos sociais de luta por moradia na área central da cidade, tal como ocorrido em São Paulo durante as gestões Luiza Erundina e Marta Suplicy, essa opção é descartada devido à avaliação negativa deste tipo de coletividade, associando sua politização a uma suposta "manipulação" de seus membros.
Em São Paulo, as pessoas querem se enquadrar num financiamento da CEF, querem se organizar, morar e pagar por aquilo. Não estão somente pedindo os imóveis. No Rio é diferente, pois as pessoas querem ganhar os imóveis. E existem forças políticas por trás desses movimentos. É uma gente muito manipulada, com menos consciência. (Informação verbal fornecida por arquiteta do PNA em junho de 2010)

A atuação da Prefeitura no processo de desocupação dos imóveis selecionados para reforma é também representativa dessa incompatibilidade do poder público municipal com princípios fundamentais de direito à moradia encarnados por esses movimentos sociais. Entrevistas com moradores das unidades habitacionais produzidas pelo PNA revelam que são poucas as famílias remanescentes do período anterior à intervenção, relatando um processo de remoção forçada, fato confirmado por uma assistente social da Prefeitura que acompanhou o processo de desocupação de alguns desses edifícios. ${ }^{10}$

A grande maioria dos moradores não quis ficar no imóvel após a reforma e preferiram sair porque não queriam pagar as taxas que passariam a ser obrigatórias. Eles deram o jeito deles [...] Muitas pessoas depois da reforma não puderam voltar porque antes não pagavam nada, $e$ agora teriam que pagar a taxa condominial, conta de água, conta de luz. E não tinham condições de arcar com esse custo mensal. A Prefeitura não tem condições de arcar com o ônus de uma pessoa que não tem condições de pagar essas taxas mensalmente. (Informação verbal fornecida por assistente social da Prefeitura em agosto de 2010) 
No entanto, de acordo com técnicos envolvidos no processo de desapropriação engendrado pelo poder público, uma maior vigilância da sociedade civil teria gerado uma modificação no padrão de retomada dos imóveis reabilitados.

Antigamente, a gente entrava e fazia. Depois, a nossa dificuldade passou a ser de intervir em imóveis ocupados, o que não era complicado antes. Nós não podemos entrar num cortiço e tirar aquelas pessoas dali sem colocá-las em outro lugar [...] Agora, é preciso oferecer bolsa aluguel ou oferecer outro imóvel. (Informação verbal fornecida por arquiteta do PNA em junho de 2010)

A criação do programa Minha Casa Minha Vida (MCMV) e do projeto Porto MaraviIha, ambos iniciados em 2009, impactaram diretamente as ações do PNA. Primeiramente, o programa habitacional do governo federal extingue as linhas de crédito disponibilizadas anteriormente pelo CEF, impondo novas regras de financiamento para a produção de moradias que estabelecem modificações tanto no perfil socioeconômico do público atendido, com a inclusão de famílias de baixíssima renda, quanto na tipologia dos imóveis construídos - unidades com dois quartos.

A partir da gestão Eduardo Paes, o objetivo é atender a população através do MCMV. Querem que os projetos contemplem famílias de 0 a 3 salários mínimos, mas nós vemos isso com muita desconfiança. Como essas famílias vão manter esse patrimônio após a ocupação? [...] Querem que produzamos habitação em grande quantidade e de baixo custo, mas isso é complicado em prédios históricos. Com o MCMV existe uma pressão para atendermos famílias maiores. Estão impondo o MCMV sem uma reflexão sobre as especificidades da área central. (Informação verbal fornecida por arquiteta do PNA em junho de 2010)

0 lançamento da operação Porto Maravilha renova a missão do PNA, desta vez como componente habitacional do projeto de revalorização da antiga zona portuária carioca. As ações do programa passam a se concentrar no perímetro de intervenção do projeto, com destaque para os arredores da Rua do Livramento, no bairro da Gamboa, onde pretende fomentar um volume inédito de unidades habitacionais nos próximos anos. Essa opção é relatada pelos técnicos como uma estratégia para garantir maior visibilidade às ações do programa.

No PNA, nós produzíamos empreendimentos isolados, e isso não dava visibilidade ao programa, pois a distância entre um imóvel e outro era muito grande. Hoje, nós estamos cientes de que a reabilitação urbana precisa concentrar esforços numa só região. (Informação verbal fornecida por arquiteto e gerente do PNA em fevereiro de 2010)

Respaldada pelo financiamento disponibilizado através do programa MCMV, a Prefeitura tem realizado nos últimos quatro anos uma série de desapropriações no entorno da Rua do Livramento. Até agosto de 2013, 21 empreendimentos já haviam sido licenciados para obras - sendo 94 unidades habitacionais destinadas a famílias com renda de 0 a 3 salários mínimos e 235 unidades para a faixa de 3 a 6 salários mínimos. Os trabalhos de campo realizados apontam que muitos dos futuros empreendimentos serão erguidos em imóveis e terrenos anteriormente ocupados 
por cortiços e autoconstruções e que hoje encontram-se vazios, com suas portas e janelas lacradas por tijolos, à espera do início das obras. Entrevistas com os moradores remanescentes na área revelam que uma parcela das famílias desalojadas teria sido contemplada com unidades habitacionais do MCMV em outros bairros da cidade, principalmente na zona oeste, em conjuntos residenciais localizados a cerca de $30 \mathrm{~km}$ da área central carioca. A outra parcela estaria recebendo o chamado "aluguel social", um cheque mensal fornecido pela Prefeitura para o pagamento de despesas com moradia. A incompatibilidade do valor oferecido pelo poder público municipal com a realidade do mercado de aluguéis na cidade estaria obrigando os beneficiários a proverem sua carência habitacional através do realojamento em cortiços da própria área central, como relata uma moradora.

Eu morava num cortiço aqui da Rua do Livramento. Éramos umas 15 famílias [...] A Prefeitura paga o "aluguel social", mas com esse dinheiro não dá pra alugar nem uma casa na favela [...] Eles ofereceram um MCMV lá em Campo Grande [bairro da Zona Oeste], mas eu vou fazer o que lá? Eu trabalho aqui no Centro, ia gastar uma fortuna com passagem de ônibus. Então arrumei um quarto num casarão aqui mesmo, e estamos morando lá. (Informação verbal fornecida por moradora da Rua do Livramento em fevereiro de 2014)

Instrumentalizada com o objetivo de auxiliar no processo de "revitalização" da área central carioca, a produção de habitações de interesse social promovida pelo poder público municipal tem corroborado com o fenômeno de segregação socioespacial, através da realocação de famílias para imóveis do programa MCMV erguidos nas franjas periféricas da cidade. 0 mesmo processo também tem corroborado com a precarização das condições de habitabilidade dos moradores desalojados - que impossibilitados de acessar o mercado formal de aluguéis, passam por um processo de realojamento nos cortiços já sobrepopulados da zona central.

Dessa forma, o programa federal de provisão habitacional tem cumprido um duplo papel no Rio de Janeiro: de um lado, garante financiamento para que imóveis patrimoniais sejam reformados, auxiliando no processo de revalorização da zona portuária carioca. De outro, possibilita que o estoque de moradias construídos nas periferias da cidade sirva como objeto de barganha no processo de desalojamento de famílias de baixa renda da região.

Complementando esse cenário, a associação do PNA à operação urbana Porto Maravilha garante que as unidades habitacionais produzidas pelo programa no perímetro de intervenção do projeto passem a fazer parte do pacote de "compromissos sociais" assumidos por seus responsáveis, contribuindo para a legitimidade das intervenções e de forma a atenuar as críticas ao projeto. ${ }^{11}$

Diferentemente do que vem sendo relatado na literatura internacional em torno do processo de gentrificação de áreas alvos de projetos de revalorização urbana - em que moradores de baixa renda seriam gradativamente substituídos por outras de classes abastadas (Smith, 1996) -, na zona portuária carioca esse fenômeno não pôde ainda ser confirmado. Observações revelaram que, até o momento, a transformação do perfil socioeconômico da região ocorre pela substituição de moradores com baixíssimos rendimentos - 
despejados dos imóveis encortiçados alvo de reabilitação - por outros de baixa renda - que futuramente ocuparão os novos imóveis financiados pelo programa MCMV destinados a famílias com renda entre 0 e 6 salários mínimos.

Considerando que o investimento do setor imobiliário tem se dirigido para os grandes vazios existentes na zona portuária - ignorando, pelo menos temporariamente, o conjunto arquitetônico formado pela área de proteção ambiental ${ }^{12}$ onde se concentra grande parte dos cortiços e ocupações da região -, é prematuro afirmar que um processo de transformação do perfil socioeconômico estaria em curso. ${ }^{13} \mathrm{Na}$ opinião de um empresário da construção civil entrevistado, as garantias de um ambiente seguro para o investimento do capital imobiliário do setor habitacional ainda não se concretizaram.

Aqueles prédios comerciais espelhados que estão sendo erguidos na zona portuária, moderníssimos, lembram uma Dubai. Mas no entorno, você encontra todo aquele casario decadente, que mais parece uma Calcutá. Estão construindo uma Dubai cercada de Calcutá. 0 grande problema na área do porto é aquele casario, nenhum empresário está tendo interesse de viabilizar empreendimentos nesses imóveis. Os vazios urbanos não são um problema, todos aqueles terrenos vazios do porto serão comercializados [...] Uma família de classe média compra um imóvel tendo em mente que está realizando um investimento. Ela não quer morar e nem investir num bairro tomado por cortiços, invasões e imóveis abandonados. (Informação verbal fornecida por empresário da construção civil em março de 2014)

Assim, a consideração de Gaffney (2013) sobre a evidência do processo de "gentrificação" em curso na zona portuária parece precoce, visto que o estabelecimento da classe média nos setores mais populares da região é ainda virtual. ${ }^{14}$ Essa constatação, no entanto, não contradiz a evidência do caráter elitizante da operação urbana em curso, desvelado tanto pelo desenho institucional do projeto quanto pelos impactos das ações nos últimos cinco anos de sua realização.

0 desinteresse do capital imobiliário nesse tipo de investimento contrasta, no entanto, com o crescimento populacional constatado pelo último censo demográfico. Após décadas de declínio, o número de residentes nos bairros centrais da cidade registra acréscimos que em alguns casos superam a população total evidenciada pelo recenseamento de 1991 (Tabela 2).

Tabela 2 - Evolução da população residente (1980-2010)

\begin{tabular}{l|c|c|c|c|c|c|c}
\hline \multicolumn{1}{c|}{ Bairro } & 1980 & 1991 & $\mathbf{2 0 0 0}$ & $\mathbf{2 0 1 0}$ & $\begin{array}{c}\text { Variação } \\
\mathbf{1 9 9 1 / 1 9 8 0}\end{array}$ & $\begin{array}{c}\text { Variação } \\
\mathbf{2 0 0 0 / 1 9 9 1}\end{array}$ & $\begin{array}{c}\text { Variação } \\
\mathbf{2 0 1 0 / 2 0 0 0}\end{array}$ \\
\hline Centro & 55.095 & 49.095 & 39.135 & 41.142 & $-10.8 \%$ & $-20.2 \%$ & $5.1 \%$ \\
Gamboa & 15.767 & 11.507 & 10.490 & 13.108 & $-27 \%$ & $-8.8 \%$ & $24.9 \%$ \\
Santo Cristo & 14.882 & 12.340 & 9.618 & 12.330 & $-17 \%$ & $-22 \%$ & $28.1 \%$ \\
Saúde & 3.655 & 2.602 & 2.186 & 2.749 & $-28.8 \%$ & $-15.9 \%$ & $25.7 \%$ \\
\hline
\end{tabular}

Fonte: IBGE. Censos Demográficos 1980, 1991, 2000 e 2010. 
Considerando-se que o número de empreendimentos residenciais lançados nas duas últimas décadas na região é incompatível com o crescimento demográfico apresentado pelos dados do Censo 2010, sugerem-se duas hipóteses para explicar o fenômeno.

Primeiramente, a hipótese de que uma migração intraurbana estaria incrementando o número de moradores na região via diminuição da vacância imobiliária. A valorização fundiária em toda cidade contribuiria para um aumento da demanda de imóveis residenciais nos bairros centrais, que se tornaram uma alternativa mais viável para determinadas faixas de renda - não apenas pelos valores imobiliários abaixo da média dos praticados em bairros das zonas sul e norte carioca, mas também pelas vantagens em termos de acessibilidade ao mercado de trabalho, serviços e transporte público. ${ }^{15}$

A segunda hipótese é de que o adensamento vem ocorrendo mediante o aumento da informalidade das formas de provisão de moradia, ou seja, pelo aumento de famílias residentes nas favelas e cortiços da zona central da cidade. Confirmada essa hipótese, estaríamos diante de um afastamento do ideário de "revitalização" formulado pelo poder público municipal, que enseja o adensamento populacional mediante a atração da classe média, criando no centro do Rio de Janeiro um espaço socialmente heterogêneo compatível com a retórica prevalecente de "mistura social".

Estudos mais precisos possibilitarão traçar um perfil socioeconômico dos novos moradores, provocando discussões sobre os impactos do processo de revalorização urbana em curso.

\section{Considerações finais}

0 estudo sobre a produção de habitação de interesse social na área central do Rio de Janeiro, promovida pelo poder público municipal, conduz a uma série de reflexões ao revelar pontos negligenciados pelo discurso oficial e ignorados pelos defensores do adensamento populacional dos centros urbanos.

A pesquisa revelou que, nas duas últimas décadas, os recursos públicos destinados ao fomento de unidades habitacionais para famílias de baixa renda têm sido orientados pela lógica de especulação imobiliária dos bairros centrais da cidade. A instrumentalização da habitação de interesse social ao imperativo de revalorização - travestido sob o conceito de "revitalização" - baseia-se na premissa de que a reforma de imóveis patrimoniais e a ocupação de vazios urbanos seriam capazes de promover uma "contaminação positiva" em seus entornos como a reanimação da atividade comercial e a dinamização do mercado imobiliário. ${ }^{16}$

Demonstra-se também que as intervenções protagonizadas pelo poder público nos bairros centrais do Rio de Janeiro distanciam-se do ideário de cidade inclusiva, preconizado por setores progressistas e movimentos sociais de luta pela reforma urbana e direito à moradia digna. Em sua ação de reabilitação de imóveis patrimoniais, a Prefeitura não contempla integralmente as unidades residenciais previamente existentes, uma situação que gera a diminuição do estoque de unidades e a consequente degradação das condições de habitabilidade das populações encortiçadas. Essa realidade tem sido potencializada com o grande volume 
de investimentos federais para o setor habitacional disponibilizado pelo programa Minha Casa Minha Vida, que vem destinando parte de seus recursos para a construção de moradias sociais na área central do Rio de Janeiro - em especial no perímetro de atuação da mais recente tentativa de revalorização do centro da cidade, a operação urbana Porto Maravilha. ${ }^{17}$

As informações recolhidas junto aos moradores da zona portuária confirmam as denúncias de que as remoções ocorrem desvinculadas dos preceitos básicos de direito à cidade e à moradia juridicamente previstos, uma situação que não é, todavia, uma excepcionalidade do caso analisado. ${ }^{18}$ Apesar da criação de um amplo aparato legal que regulamenta a política urbana - no qual se destaca a promulgação do Estatuto da Cidade - e uma série de diretivas e documentos oficiais que contemplam a necessidade manutenção do caráter popular dos bairros centrais, ${ }^{19}$ observa-se, por via de regra, que os grandes projetos urbanos em execução aprofundam os traços elitistas e excludentes da política urbana brasileira, tornando a permanência das populações pobres a princípio irreconciliável diante da lógica da revalorização imobiliária que dirige essas intervenções.

Portanto, tão importante quanto a discussão sobre os desdobramentos da revalorização dos bairros centrais para as populações locais é a reflexão sobre a racionalidade que rege as políticas urbanas em um contexto marcado pela neoliberalização. No caso do Rio de Janeiro, diretrizes da política urbana que a princípio comporiam uma agenda redistributiva e progressista do desenvolvimento urbano - 0 readensamento da área central e o fomento à produção de habitação de interesse social acabam sendo capturadas por lógicas corporativas de produção do espaço. Especialmente no caso das operações urbanas estabelecidas a partir de parcerias público-privadas, nas quais a rentabilidade dos investidores se sobrepõe aos interesses coletivos, as disparidades entre projetos de cidade tornam mais evidente a incompatibilidade entre o ímpeto da valorização fundiária e a garantia do direito à moradia adequada das populações de baixa renda.

\section{João Carlos Carvalhaes dos Santos Monteiro}

Université du Québec à Montréal, Département d'Études Urbaines et Touristiques. Montreal, Canadá. joaocarlosmonteiro@gmail.com 


\section{Notas}

(*) Uma versão preliminar deste artigo foi publicada nos anais do XVI Encontro Nacional da Associação Nacional de Pós-graduação e Pesquisa em Planejamento Urbano e Regional, realizado em Belo Horizonte, em maio de 2015. Parte das conclusões é fruto de uma pesquisa no âmbito de um mestrado em Planejamento Urbano e Regional (Ippur/UFRJ) sob orientação da Profa. Dra. Luciana Correa do Lago. Agradeço os comentários de Eduardo Sombini, Helena Galiza e Julia Cossermelli de Andrade que contribuíram na elaboração do artigo, assumindo, no entanto, plena responsabilidade pelas ideias expostas.

(1) Entre os anos de 2010 e 2014 foram realizadas entrevistas com cinco arquitetos funcionários e exfuncionários da Prefeitura alocados na gerência do Programa Novas Alternativas, um ex-gerente e o gerente do programa à data, além de uma assistente social da Prefeitura responsável pelo trabalho social com os moradores dos imóveis alvo de intervenções. No primeiro semestre de 2010, foram realizadas entrevistas com 24 moradores dos três imóveis selecionados no estudo, um número que representa $60 \%$ do total de unidades ocupadas nesses três imóveis. Para mais informações sobre a metodologia utilizada na pesquisa, consultar Monteiro (2011).

(2) A teoria dos "efeitos multiplicadores" é um dos princípios que regem o paradigma neoclássico de desenvolvimento difundidos por organismos internacionais como o Banco Mundial. Ramsamy (2006) fornece uma análise crítica sobre a agenda urbana no banco.

(3) O GLOBO. De volta às origens. Publicado em 21/8/2005. O empreendimento em questão é o condomínio Cores da Lapa, inaugurado em 2005. Seus 688 apartamentos foram vendidos em menos de duas horas, provocando entusiasmo dos gestores municipais quanto ao potencial de demanda por unidades habitacionais nos bairros centrais. Esse entusiasmo, no entanto, não foi compartilhado entre os empresários da construção civil, e apenas um novo empreendimento residencial foi inaugurado na região desde então - o condomínio Viva Lapa, de 178 apartamentos, resultado de uma operação de retrofit.

(4) As tentativas de transformação remontam aos anos 1980, quando a Associação Comercial do Rio de Janeiro propôs a construção de um centro de negócios na região. No início dos anos 2000, o então prefeito César Maia ensaiou a construção de uma filial do Museu Guggenheim no âmbito de um projeto de "revitalização" da zona portuária. Ambos os projetos não foram adiante, seja pela falta de recursos, quanto pela oposição de setores da sociedade civil.

(5) Instituem, entre outras ações, a remissão de dívidas municipais, a isenção de Imposto Predial e Territorial Urbano (IPTU) e Imposto sobre Transmissão de Bens Imóveis (ITBI), a flexibilização de área mínima construída, a dispensa da obrigação de garagem e a permissão de remembramento de lotes.

(6) O relato pessoal de Barbosa e Pita (2006) constitui uma importante fonte de informações sobre a trajetória do movimento de luta por moradia em São Paulo.

(7) Para uma recomposição desse período, consultar Azevedo (1988; 2007) e Cardoso (2003).

(8) Os demais programas que compunham a SMH em seus primeiros anos eram: Programa Favela-bairro, Programa Bairrinho, Programa Grandes Favelas, Programa de Regularização Fundiária e Titulação, Programa Morar Carioca, Programa Morar Legal e Programa Morar Sem Risco. 
(9) A promoção do uso residencial na área central carioca também motivou a elaboração de um plano de habitação de interesse social pelo governo estadual (Governo, 2011), instigada por uma experiência-piloto de reabilitação de um próprio estadual ocupado por famílias sem-teto. Lançado em 2011, o plano previa a criação de 507 unidades habitacionais para famílias com renda entre 0 e 6 salários mínimos através da reforma e construção de 50 imóveis. Nenhuma das intervenções previstas foi realizada até o momento. Sobre a experiência de reabilitação do projeto-piloto, consultar Galiza (2009).

(10) Não foi possível obter da Prefeitura o número exato de famílias remanescentes contempladas com imóveis do PNA. Em um dos imóveis reformados com financiamentro da CEF, das 23 unidades criadas, apenas uma era ocupada por uma moradora do período pré-reforma - a única elegível ao financiamento do programa de arrendamento residencial disponibilizado pelo banco.

(11) A obrigatoriedade da elaboração de um plano de habitação de interesse social para operações urbanas consorciadas que utilizam recursos do FGTS (Instrução Normativa 33, de 17/12/2014) levou a Prefeitura e a Companhia de Desenvolvimento Urbano da Região do Porto do Rio de Janeiro (CDURP) a produzirem um documento contendo diretrizes para implementação de moradias sociais no perímetro do projeto Porto Maravilha (Prefeitura, 2015).

(12) Em 1988 foi promulgada a lei que define como área de proteção ambiental parte dos bairros portuários de Santo Cristo, Gamboa e Saúde (APA Sagas), tutelando, preservando e tombando os imóveis no perímetro delimitado pelo decreto.

(13) Um único empreendimento residencial de grande porte teve as obras iniciadas no perímetro do projeto. Trata-se do condomínio Porto Vida, com 1.333 apartamentos, erguido em antigo terreno da RFFSA, fora da área de proteção ambiental. O projeto abrigaria acomodações para árbitros, jornalistas e funcionários dos Jogos Olímpicos Rio 2016 e após o evento seria entregue aos compradores. Em meados de 2014, a Prefeitura decidiu transferir as acomodações para um outro projeto residencial que está sendo erguido no bairro do Anil, zona oeste da cidade. As obras do Porto Vida encontram-se desde então paralisadas e uma parte do projeto poderá ser convertida para uso comercial.

(14) Da mesma maneira, faz-se necessária uma reflexão crítica sobre o uso do conceito de "gentrificação" para a realidade brasileira. Para um debate introdutório sobre o tema, consultar Lees (2014).

(15) O GLOBO. Zona portuária já atrai moradores antes de revitalização ser concluída. Publicado em 4/11/2012.

(16) Esta tentativa, no entanto, mostrou-se frustrada e, em muitos dos casos analisados, constata-se um retorno à situação de degradação física dos imóveis reformados. Isso se deve principalmente à falta de manutenção predial. Os moradores contemplados com unidades residenciais do PNA alegam não conseguir arcar com os custos de manutenção exigidos por imóveis patrimoniais. A Prefeitura, a CEF e os órgãos de preservação do patrimônio envolvidos na reforma dos imóveis, por sua vez, eximem-se desta responsabilidade (Monteiro, 2011). 
(17) Em São Paulo, a criação de uma PPP da Habitação para a área central da cidade é o mais recente exemplo dessa convergência entre projetos de habitação de interesse social e revalorização urbana. De iniciativa do governo estadual, com parceria da Prefeitura, a primeira fase do programa prevê ofertar 3.683 unidades habitacionais - 2.260 de interesse social (1 a 6 s.m.) e 1.423 de mercado popular (6 a 10 s.m.). Após o fracasso das iniciativas de "revitalização" anteriores, cujo exemplo emblemático é o cancelamento do projeto Nova Luz, o programa é a nova aposta do poder público para dinamizar a atividade imobiliária na área central de São Paulo. Em muitos aspectos, identificam-se convergências entre as propostas e ações promovidas na metrópole paulista daquelas observadas na sua congênere fluminense, tais como, no plano discursivo, a ênfase no imperativo de readensamento dos bairros centrais e a busca por uma "mistura de classes sociais" (retórica da mixité sociale), e, no âmbito da composição financeira, o apelo a recursos do governo federal mediante repasses do programa MCMV. Sobre o tema, consultar Sombini (2015).

(18) De maneira geral, as recentes obras de mobilidade urbana e os grandes projetos atrelados aos eventos esportivos a serem realizados na cidade do Rio de Janeiro reproduzem esta conduta. Um dossiê elaborado pelo Comitê Popular da Copa e Olimpíadas do Rio de Janeiro relata esses casos (Comitê, 2013). Na zona portuária, essa situação não é exclusiva da Rua do Livramento e seu entorno. Moradores de ocupações sem-teto e favelas inseridas no perímetro do projeto Porto Maravilha também enfrentam situação semelhante, como nos casos dos morros da Providência e Pedra Lisa.

(19) Pode-se citar inúmeros documentos produzidos pelo Ministério das Cidades (Brasil, 2005; 2008; 2011).

\section{Referências}

ABREU, M. (2006). Evolução urbana do Rio de Janeiro. Rio de Janeiro, IPP.

AZEVEDO, P. (1973). Contribuição à criação de uma legislação específica para setores monumentais ou paisagísticos. In: IPHAN - II Encontro de Governadores para Preservação do Patrimônio Histórico, Artístico, Arqueológico e Natural do Brasil. Anais. Salvador, 25 a 29 de outubro.

(1978). Recuperação do patrimônio habitacional como alternativa complementar ao problema da moraria no Brasil. In: BNH. Simpósio sobre Barateamento da Construção Habitacional. Salvador, 26 a 31 de março.

AZEVEDO, S. (1988). Vinte e dois anos de política de habitação popular (1964-86): criação, trajetória e extinção do BNH. Revista de Administração Pública, v. 22, n. 4, pp. 107-119.

(2007). "Desafios da habitação popular no Brasil: políticas recentes e tendências". In: CARDOSO,

A. (coord.). Habitação social nas metrópoles brasileiras: uma avaliação das políticas habitacionais em Belém, Belo Horizonte, Porto Alegre, Recife, Rio de Janeiro e São Paulo no final do século XX. Porto Alegre, Antac.

BARBOSA, B. e PITA, S. (2006). A trajetória das lutas do Centro: das ocupações e resistência às conquistas. Curso de Capacitação - Programas de reabilitação de áreas urbanas centrais. Lincoln Institute of Land Police/LABHAB. 
BID; PCRJ; APUR (2008). Relatório de diagnóstico do Plano de Revitalização da área central do Rio de Janeiro. Rio de Janeiro, BID/PCRJ/APUR.

BOSI, V. (1986). Núcleos históricos: recuperação e revitalização; a experiência de Olinda. Revista do Patrimônio Histórico e Artístico Nacional, n. 21.

BRASIL (2005). Reabilitação de centros urbanos. Brasília, Ministério das Cidades.

(2008). Manual de reabilitação de áreas urbanas centrais. Brasília, Ministério das Cidades.

(2011). Implementação de ações em áreas urbanas centrais e cidades históricas: manual de orientação. Brasília, IPHAN/Ministério das Cidades.

CARDOSO, A. (2003). Política habitacional no Brasil: balanço e perspectivas. Revista Proposta, n. 95, ano 30, pp. 6-17.

CARDOSO, A. e RIBEIRO, L. (2002). “Os municípios e as políticas habitacionais”. In: ABIKO, A. e ORNSTEIN, S. (eds.). Inserção urbana e avaliação pós-ocupação (APO) da habitação de interesse social. São Paulo, FAUUSP.

COMITÊ POPULAR DA COPA E OLIMPÍADAS DO RIO DE JANEIRO (2013). Megaeventos e violações dos direitos humanos no Rio de Janeiro. Dossiê do Comitê Popular da Copa e Olimpíadas do Rio de Janeiro.

GAFFNEY, C. (2013). Forjando os anéis: a paisagem imobiliária pré-olímpica no Rio de Janeiro. E-metropolis, n. 15, ano 4, pp. 6-20.

GALIZA, H. (2009). Política urbana federal de reabilitação de centros antigos: debates e diretrizes sobre habitação e inclusão social. Dissertação de mestrado. Niterói, Universidade Federal Fluminense.

GOVERNO DO ESTADO DO RIO DE JANEIRO (2011). Plano de Reabilitação e Ocupação dos Imóveis do Estado do Rio de Janeiro na área central da Cidade do Rio de Janeiro. Rio de Janeiro, Governo do Estado do Rio de Janeiro/Governo Federal do Brasil/Fundação José Bonifácio/FAU-UFRJ/LabhabUFRJ.

HARVEY, D. (1989). From managerialism to entrepreneurialism: the transformation in urban governance in late capitalism. Geografiska Annaler, v. 71, n. 1, pp. 3-17.

HILLMAN, M. (1996). "In favour of the compact city”. In: BURTON, E.; JENKS, M. e WILLIAMS, K. (eds.). The compact city: a sustainable urban form? Londres, Routledge.

LEES, L. (2014). “Gentrification in the global south?”. In: PARNELL, S. e OLDFIELD, S. (eds.). The routledge handbook on cities of the global south. Londres, Routledge.

MONTEIRO, J. (2011). Habitação social na área central do Rio de Janeiro: reflexões críticas a partir do Programa Novas Alternativas. Dissertação de mestrado. Rio de Janeiro, Universidade Federal do Rio de Janeiro.

MONTEIRO, J. e ANDRADE, J. (2012). Porto Maravilha a contrapelo: disputas soterradas pelo grande projeto urbano. E-metropolis, n. 8, ano 3, p. 21-31.

PREFEITURA DA CIDADE DO RIO DE JANEIRO (2003a). A retomada do Centro da cidade. Coleção Estudos Cariocas, n. 20030601.

(2003b). Novas Alternativas: projetos e propostas habitacionais para o Rio de Janeiro. Rio de Janeiro, SMH. 
PREFEITURA DA CIDADE DO RIO DE JANEIRO (2005). Plano diretor decenal de 1992: subsídios para sua revisão. Coleção Estudos Cariocas, n. 20051203.

(2015). Plano de habitação de interesse social do Porto Maravilha. Rio de Janeiro, Prefeitura da Cidade do Rio de Janeiro.

RAMSAMY, E. (2006). The World Bank and urban development: from projects to policy. Londres, Routledge.

SANTOS, M. (1979). Oespaço dividido: os dois circuitos da economia urbana dos países subdesenvolvidos. Rio de Janeiro, Ferreira Alves.

SMITH, N. (1996). The new urban frontier: gentrification and the revanchist city. Londres/Nova York, Routledge.

SOMBINI, E. (2015). Grandes projetos urbanos, parcerias público-privadas e usos corporativos do território da área central de São Paulo. Relatório de pesquisa, Campinas, IG/Unicamp.

Texto recebido em 5/abr/2015

Texto aprovado em 24/jul/2015 
